\title{
A Correlational Study Between Reading Comprehension, Sentence Structure Mastery and Paraphrasing Skill
}

\author{
Ulfa Putri Arifah, Suparno, Endang Setyaningsih
}

\author{
English Education Department \\ Teacher Training and Education Faculty \\ Sebelas Maret University of Surakarta
}

\author{
Email: ulfaputriarifah@gmail.com
}

\begin{abstract}
The article aims at reporting and discussing the finding of the correlation between reading comprehension, sentence structure mastery and paraphrasing skill. The research was conducted to the fifth semester students of a University in Surakarta in December 2013. The population of the study is all of the fifth semester students while the sample is 30 students taken by using cluster random sampling technique. The instruments used for collecting data are objective test is used to collect reading comprehension and sentence structure mastery data, and essay test to collect data of paraphrasing skill. The techniques used to analyze the data are Single Correlation and Multiple Regression Correlation. The result of analysis indicates that reading comprehension and sentence structure mastery give significant positive contribution to paraphrasing skill; both partially and simultaneously. It means reading comprehension and sentence structure mastery can be used to estimate paraphrasing skill.
\end{abstract}

Keywords: correlation, reading comprehension, sentence structure mastery, paraphrasing skill

\section{INTRODUCTION}

For centuries, it is popular to use international journals and texts to support researches and studies in academic field. Especially in Indonesia, there are many teachers and instructors who suggest their students to read as much as possible texts from foreign writers to gain information which they cannot get from local writers. After reading many resources from the text, the students are supposed to write their academic composition based on the information they already got. In the process of doing their work, supporting their own ideas with ideas from various sources is necessary. According to Campbell (1990), the competence of combining ideas and information from related previous researches is one of factors in a successful academic writing. He further claimed "even the most original academic paper integrates facts, ideas, concepts and theories from other sources by means of quotations, paraphrases, summaries and brief references" (p. 211).

In process of composing academic writing, students should be careful in borrowing other's ideas and have to avoid plagiarism. Dealing with this, the students were asked to do a correct citation. In his research about paraphrasing skill, Syafei (2013, p. 495) found that some students tend to copy word by word from the sources in the process of composing academic paper. He further found that the students also didn't cite correctly. It can make the students were guilty of plagiarism. Oshima and Hogue (2006, p. 41) pointed out that quoting, paraphrasing and summarizing are the strategies that can be used to take ideas from sources without doing plagiarism. 
It is nearly impossible to quote every sentence and paragraph to support their academic paper. For that reason, students can use paraphrasing beside quotation. Spears (2000, p. 12) defined paraphrasing as rewriting the words from the text by using the writer's own words and restating the same ideas. Spears also stated that paraphrasing can be reached through substituting synonyms for a key word or word in original, changing the order of the ideas within sentences, or combining ideas whenever it is possible. Likewise, Oshima and Hogue (2006, p. 41) explained that paraphrasing is presenting ideas from reading text with reader's own words without change the meaning of the sources. Furthermore; they provided three keys to compose a good paraphrase: 1) the writer uses his/her own words and his/her own sentence structure; 2) the paraphrase has approximately the same number of words as the original passages; 3 ) the meaning of the original passage does not change (p.129).

Thus, paraphrasing skill in this study is a process of rewriting or restating idea from a source using different words, substituting synonyms for a key word or word in original, and changing the order of the ideas within sentences without changing the original meaning.

Paraphrasing is probably hard to do if the students do not have a good reading comprehension. The research conducted by Shabani \& Abbasi (2011), with 60 Iranian sophomore students in English Language Department of Azad University as the subject, found that there is a positive correlation between paraphrasing and reading comprehension (p. 519). In addition, Syafei (2013) stated that "poor paraphrases might be caused by lack of reading comprehension skills, lack of vocabulary and grammar knowledge and lack of writing (or paraphrasing) skills of the students" (p. 497). A good reading comprehension is required in paraphrasing since they have to read the text comprehensively and know the exact meaning from the author (Lane, 2011, p. 1).

Aebersold and Field (1997) defined reading as a great activity which gives the reader information, perception and different thought (p. 6). Reading process exists when reader reads a text and gets the meaning from it. They further believe that in reading process, reader and text are the most important variables needed (p. 15). While, Grellet (1999) defined reading comprehension as ability in recognizing a text and gaining information needed from the text effectively. The reader need to associate between the sentences manifested in the text and the meaning of the text correctly (p. 3 ).

Thus, reading comprehension in this study can be defined as ability of gaining and assigning meaning or information from a text effectively which gives the reader knowledge, perception and different thought. Here, we can notice that reader, text, and interaction between them are the most essential entities.

One of the things Syafei (2013, p. 497) stated which can affect paraphrasing is grammar knowledge, in this case is the mastery of sentence structure. Logically in paraphrasing a text, students should know the structure of sentences. The mastery of the structure of sentence will enable students to make effective sentence in delivering and expressing ideas to others in their paraphrasing activity. The absence of sentence structure mastery will lead students to deliver different meaning from the sources they read.

Matthews (1996, p. 26) defined sentence as a set of words or phrases which construct a complete idea. In line with Matthews, Blumenthal (1963, p. 249) 
viewed sentence as a number of words that forms an idea completely. While, structure is defined as the process in positioning or arranging a particular thing (Cambridge Dictionary, 2008). In this case, structure is limited in the term of organizing or constructing idea into sentence. Anglin (2013, p. 1) further explained that sentence structure deal with the arrangement of a set of words consisting subject and verb that construct a complete idea.

Thus, sentence structure in this study is the way to arrange or organize a set of words, phrases, or clauses to express a complete idea. Meanwhile, sentence structure mastery can be defined as a comprehensive skill and knowledge in using correct structure to organize a set of words, phrase, or clauses to express a complete idea.

According to the previous theories, the researcher formulates hypotheses as follows: 1) there is a correlation between reading comprehension and paraphrasing skill; 2) there is a correlation between sentence structure mastery and paraphrasing skill; and 3) there is a correlation between reading comprehension and sentence structure mastery to paraphrasing skill simultaneously.

\section{RESEARCH METHODS}

The method used in this research is correlational method. According to Halonen \& Santock (1999: 20), correlational method is a method of which goal is to describe the relation between two or more events or characteristics. The writer uses this method because he wants to know the relationship between the three variables based on correlation coefficient. There are three variables of this research. The three variables can be divided into two independent and one dependent variables. The independent variables are reading comprehension $\left(\mathrm{X}_{1}\right)$ and sentence structure mastery $\left(\mathrm{X}_{2}\right)$, while the dependent variable is paraphrasing skill (Y).

The research was carried out in a University in Surakarta in December 2013. It was conducted to the fifth semester students in the academic year of 2013/2014. The sample of the research is 30 out of 96 students taken by cluster random sampling technique.

The instruments were used to collect the data are objective and essay test. The objective test is used to collect the data of reading comprehension. It consists of 30 items with four optional answers. Objective test is also used to collect the data of sentence structure mastery. Sentence structure mastery test consists of 41 items of multiple choice questions. Both instrument of reading comprehension and sentence structure mastery have been tried out to find the validity and realibility of the items. To take the data of the students' paraphrasing skill, the researcher used essay test. In this test, students have to paraphrase eight paragraphs.

Before testing the hypothesis, the researcher tested the normality, linearity and significance of regression as the prerequisite test. After prerequisite test is done, the next step is analyzing the data to test the hypothesis. The data of the research were analyzed using Pearson Product Moment Formula and Multiple Linear Regression. Pearson Product Moment Formula is used to find out the correlation between two variables $\left(\mathrm{X}_{1}-\mathrm{Y} / \mathrm{X}_{2}-\mathrm{Y}\right)$ and Multiple Linear Regression is used to figure out the correlation between two independent variables simultaneously and one dependent variable $\left(\mathrm{X}_{1}, \mathrm{X}_{2}-\mathrm{Y}\right)$ 


\section{RESEARCH FINDINGS AND DISCUSSIONS}

From the computation of the first hypothesis, it is found that the coefficient correlation $\left(\mathrm{r}_{\mathrm{s}_{1} \mathrm{y}}\right)$ between reading comprehension $\left(\mathrm{X}_{1}\right)$ and paraphrasing skill (Y)is 0.467 and the value of $t_{0}$ is 2.79 . After the $t_{0}$ is compared to the $t$-table at the level of significance 0.05 for $\mathrm{N}=30$, it shows that the value of $t_{0}(2.79)$ is higher than the value of $\mathrm{t}$-table (1.70); $\mathrm{t}_{\mathrm{o}}(2.79)>\mathrm{t}_{\mathrm{t}}(1.70)$. It means that the first hypothesis saying there is a positive correlation between reading comprehension $\left(\mathrm{X}_{1}\right)$ and paraphrasing skill $(\mathrm{Y})$ is accepted. Then, it shows that the increase of reading comprehension will be followed by the increase of paraphrasing skill. The coefficient determination $\left(\mathrm{r}_{\mathrm{s}_{1}} \mathrm{y}^{2}\right)$ between reading comprehension $\left(\mathrm{X}_{1}\right)$ toward paraphrasing skill $(\mathrm{Y})$ is 0.218 . It means that $21.8 \%$ paraphrasing skill is influenced by reading comprehension factor.

The second hypothesis testing shows that coefficient correlation $\left(\mathrm{r}_{2 \mathrm{y}}\right)$ between sentence structure mastery $\left(\mathrm{X}_{2}\right)$ and paraphrasing skill (Y) is 0.597 and the value of $t_{0}$ is 3.94. After the $t_{0}$ is compared to the t-table at the level of significance 0.05 for $\mathrm{N}=30$, it shows that the value of $t_{0}(3.94)$ is higher than the value of t-table (1.70); $t_{0}(3.94)>t_{t}(1.70)$. It means that the second hypothesis saying there is a positive correlation between sentence structure mastery $\left(\mathrm{X}_{2}\right)$ and paraphrasing skill $(\mathrm{Y})$ is accepted. It shows that the increase of sentence structure mastery will be followed by the increase of paraphrasing skill. The coefficient determination $\left(\mathrm{r}_{\mathrm{s}_{2}} \mathrm{y}^{2}\right)$ between sentence structure mastery $\left(\mathrm{X}_{2}\right)$ toward paraphrasing skill (Y) is 0.3574 . It means that $35.74 \%$ paraphrasing skill is influenced by sentence structure mastery factor.

The computation of multiple regression in the third hypothesis testing shows that coefficient of $\mathrm{a}_{0}, \mathrm{a}_{1}$, and $\mathrm{a}_{2}$ are $23.85 ; 0.82$; and 0.53 , so the multiple regression equation of $\mathrm{Y}$ on $\mathrm{X}_{1}$ and $\mathrm{X}_{2}$ becomes $\hat{Y}=-23.85+0.82 \mathrm{X}_{1}+0.53 \mathrm{X}_{2}$. The testing of the significance regression for $\mathrm{F}_{\mathrm{o}}$ is 8.35. After the value of $F_{o}$ is compared to $F$ table $\left(\mathrm{F}_{\mathrm{t}}\right)$ at the level significance $\alpha=0.05$, it shows that the value of $F_{0}(8.35)$ is higher than $\mathrm{F}_{\mathrm{t}}(3.35) ; \mathrm{F}_{\mathrm{o}}(8.35)>\mathrm{F}_{\mathrm{t}}(3.35)$. It means that the third hypothesis saying there is a positive correlation between reading comprehension and sentence structure mastery simultaneously to paraphrasing skill is accepted. The coefficient determination $\left(\mathrm{R}_{\mathrm{y} 12^{2}}{ }^{2}\right)$ between reading comprehension and sentence structure mastery toward paraphrasing skill is 0.3823 . It means that $38.23 \%$ variance of paraphrasing skill is determined by reading comprehension and sentence structure mastery and $61.77 \%$ variance of paraphrasing skill is determined by other factor.

The result of testing hypotheses shows that the coefficient correlation between reading comprehension, sentence structure mastery and paraphrasing skill is significant and all hypotheses indicates positive correlation. The illustration of the correlation between reading comprehension, sentence structure mastery and paraphrasing skill can be described as follows.

In learning process, students are frequently asked to make essay or academic paper. To support their essay or academic paper, they need to explore information from relevant sources. According to Campbell (1990), the competence of combining ideas and information from related previous researches is one of factors in a successful academic writing. He further claimed "even the most original academic paper integrates facts, ideas, concepts and theories from other sources by means of quotations, paraphrases, summaries and brief references" (p. 211). Because of 
impossible to quote every sentence and paragraph to support their academic paper, students can use paraphrasing beside quotation. Here, paraphrasing plays role to extract and gain the meaning of sources they read.

To gain the meaning of the sources well, students need a good reading comprehension. Being able to read comprehensively, authors' ideas or messages will be acquired by students clearly; so misunderstanding of the meaning can be avoided. A good reading comprehension will give a positive contribution in paraphrasing since the main activity of paraphrasing is know the exact meaning from the author and rewording ideas from the text (Lane, 2011, p. 1). The comprehensive understanding about implicit and explicit information will make the student get the original meaning of the text.

The research conducted by Munro (2005) in the third grade students of non English as a Second Languge (ESL), pointed out that "there is a relationship between a student's comprehension ability and their paraphrasing skills" (p. 8). Besides, Shabani \& Abbasi (2011) have conducted research, with 60 Iranian sophomore students who were studying English and translation majors in English Language Department of Azad University as the subject, found that there is a positive correlation between paraphrasing and reading comprehension ( $p$. 519).

Another aspect to produce a good paraphrasing in composing academic paper is sentence structure mastery. Borough (2012) stated that the difficulty in interpreting meaning in the sentences can cause comprehension problems. Sometimes, the student misinterpret about the content of the text because of their lack knowledge about structure (p. 3). In this case, the mastery about words, clauses and phrases will make students analyze the reading text easier. They can analyze sentence by sentence correctly and get the information needed.

Logically, the mastery of sentence structure is required in paraphrasing since the students need to convey the exact idea of the text by using their own sentence structure (Oshima and Hogue, 2006, p. 129). Being able to recognize the sentence formation and create correct sentence structure helps the students to produce clearcorrect sentence and convey the author's original ideas to readers in a written form. Whereas, the absence of sentence structure mastery will lead the students to misunderstand the author's ideas. As the result, they convey different meaning from the text they read. For the example is the use of past participle, the lack knowledge about past participle will confuse student about the function of the verb used.

From the explanation above, it is quite clear that reading comprehension and sentence structure mastery simultaneously build a good relationship and give positive contribution toward paraphrasing skill.

\section{CONCLUSIONS AND SUGGESTIONS}

From the result of the research, it can be concluded that the first hypothesis saying there is a positive correlation between reading comprehension and paraphrasing skill is accepted. The computation shows that the coefficient correlation $\left(r_{x 1 y}\right)$ is 0.467 and the value of t-obtained (2.79) is higher than the value of t-table (1.70); $t_{0}$ $(2.79)>t_{t}(1.70)$. It means that the increase of reading comprehension will be followed by the incease of paraphrasing skill. The coefficient determination $\left(\mathrm{r}_{\mathrm{s}_{1}}\right)$ between reading comprehension $\left(\mathrm{X}_{1}\right)$ toward paraphrasing skill $(\mathrm{Y})$ is 0.218 . It means that $21.8 \%$ variation of paraphrasing skill $(\mathrm{Y})$ is 
influenced by reading comprehension $\left(\mathrm{X}_{1}\right)$ and $78.2 \%$ is influenced by other factors.

The second hypothesis saying there is a positive correlation between sentence structure mastery and paraphrasing skill is accepted. The computation shows that the coefficient correlation $\left(\mathrm{r}_{\mathrm{s}_{2 \mathrm{y}}}\right)$ is 0.597 and the value of t-obtained(3.94) is higher than the value of $t$-table $(1.70) ; t_{0}(0.394)>t_{t}(1.70)$. It means that the increase of sentence structure mastery will be followed by the increase of paraphrasing skill. The coefficient determination $\left(\mathrm{r}_{\mathrm{sy}}{ }^{2}\right)$, between sentence structure mastery $\left(\mathrm{X}_{2}\right)$ toward paraphrasing skill $(\mathrm{Y})$ is 0.357 . It means that $35.74 \%$ variation of paraphrasing skill (Y) is influenced by sentence structure mastery $\left(\mathrm{X}_{2}\right)$ and $64.26 \%$ is influenced by other factors.

The third hypothesis saying there is positive correlation between reading comprehension and sentence structure mastery toward paraphrasing skill is accepted. The computation shows that the coefficient correlation $\left(\mathrm{R}_{\mathrm{y} 12}\right)$ is 0.6183 and the value of F-observation (8.35) is higher than the value of F-table (3.35); $F_{0}(8.35)>$ $\mathrm{F}_{\mathrm{t}}(3.35)$. It means that the increase of reading comprehension and sentence structure mastery simultaneously will be followed by the increase of paraphrasing skill. The coefficient determination $\left(\mathrm{R}_{\mathrm{y} 12}{ }^{2}\right)$ between reading comprehension and sentence structure mastery toward paraphrasing skill is 0.3823 . It means that $38.23 \%$ variation of paraphrasing skill is influenced by reading comprehension and sentence structure mastery factors and $61.77 \%$ the rest is determined by other factors.

Considering the contribution of reading comprehension and sentence structure mastery to paraphrasing skill mastery, it is necessary for the teacher to improve students' reading comprehension and their mastery of sentence structure. In enhancing students' reading comprehension, teacher can use various sources with different topics and level of difficulty. In this case, the use of authentic material can create a good simulation in classroom since authentic material contains up-to-date information.

Teacher should improve the students' sentence structure mastery too. The mastery of sentence structure can make students understand the reading sources easily. It also can help students in producing a good paraphrasing. Maintaining the meaning of original sources in students' paraphrasing with a clear-correct sentences is necessary to avoid understanding. Deal with paraphrasing, teachers should improve their knowledge about rules of paraphrasing skill. Further, teacher should know about how to cite properly to avoid unintentional plagiarism. The rules in paraphrasing and citation can be seen in APA, MPA and books containing citation rules.

\section{BIBLIOGRAPHY}

Aebersold, J. A.,\& Field, M. L. (1997). From reader to reading teacher: Issues and strategies for second language classrooms. Cambridge: Cambridge University Press.

Anglin, M.R. (2013). What is sentence structure?. Sparks: Conjecture Corporation. Retrieved from: http://www.wisegeek.org/what-issentence-structure.htm

Blumenthal, J., Zahner, L., Frank, R., Lazarus, A., \& Elson, E.F. (1963). The english language. New York: Harcourt, Brace, and World.

Borough, K. (2012). Kingsgate speech, language, \& reading. Retrieved from http://www.kingsgatespeech.com/Re ading_Comprehension.Website.v.05. 18.2012.pdf. April, $21^{\text {st }} 2014$. 
Campbell, C. (1990). Writing with other's words: using background reading text in academic compositions. Second language writing: research insight for the classroom. Cambridge: Cambridge University Press.

Grellet, F. (1999). Developing reading skills. Cambridge: Cambridge Press

Hallonen, Jane S and Santock, John W. 1999. Psychology: Applied and Application $3^{\text {rd }}$. USA: Mc Graw-Hill College.

Lane, A. (2011). Paraphrasing. Retrieved from http://www.iupui.edu/ uwc (Retrieved in July 1 ${ }^{\text {st }}, 2013$ ).

Matthews, P.H. (1996). Syntax. Cambridge: Cambridge university press.

Munro, J. (2005). Teaching grade three students paraphrasing skills improves their comprehension of non fictions texts. Retrieved from https://students.education.unimelb.ed u.au/LiteracyResearch/pub/Projects/ D_Maslen.pdf

Oshima, A., \& Ann H. (2006). Writing academic English. New York: Pearson Education, Inc.

Shabbani, G., \& Abbasi, S. (2011). The degree of the effectiveness of paraphrasing vs summarization as reading tasks. 2011 International conference on languages, literature, and linguistics. 26, 516-520.

"Structure". (2008). Cambridge advanced learner's dictionary. $3^{\text {rd }}$ ed. Cambridge: Cambridge University Press.

Spears, D. M. (2000). Improving reading skill. Boston: McGraw Hill.

Syafei, M. (2013). Paraphrasing skill of eed students of UMK: A preliminary error analysis. Current belief in ELT and its implication in English classroom, 495-501. ISBN: 978-60214018-0-4.
Weber, R., Brizee, A. (2013). Strategies for variation. Retrieved from: https://owl.english.purdue.edu/owl/re source/573/01/ 